
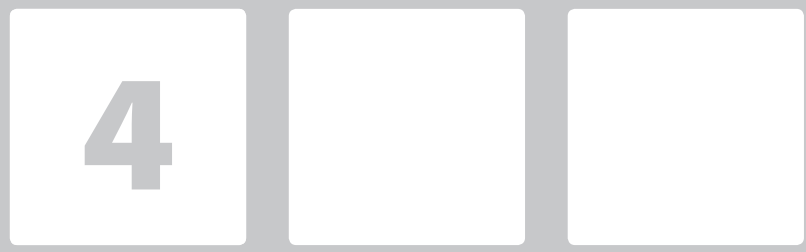

\title{
O PRINCÍPIO CONSTITUCIONAL DA IMPESSOALIDADE E A SELEÇÃO POR COMPETÊNCIAS NAS UNIVERSIDADES PÚBLICAS FEDERAIS BRASILEIRAS
}

\section{The Constitutional Principle of Impersonality and Selection by Competences in the Brazilian Federal Public Universities}

\section{Ruy Tadeu Mambrini Ribas}

Mestre. Servidor Técnico-Administrativo. Universidade Federal de Santa Catarina. Blumenau, SC. Brasil.e-mail: ruy.ribas@ufsc.br

\section{Gabriela Mattei de Souza}

Mestre. Servidora Técnico-Adm. Universidade Federal de Santa Catarina. Florianópolis, SC. Brasil.e-mail:gabrielagmds@gmail.com

\section{Cristiane Laurentino Silva}

Mestre. Servidora Técnico-Administrativo. Instituto Federal de Santa Catarina. São José, SC. Brasil.e-mail: cris.laurentino2@gmail.com

\section{Marcos Baptista Lopez Dalmau}

Doutor. Docente do Departamento de Ciencias da Administração. Universidade Federal de Santa Catarina. Florianópolis, SC. Brasil. e-mail:marcos.dalmau@ufsc.br

\section{RESUMO}

O presente estudo realizou uma análise da compatibilidade do princípio constitucional da impessoalidade com a utilização da seleção de pessoas por competências no âmbito das universidades públicas federais. Por meio do levantamento teórico sobre os temas abordados, foi possível realizar um raciocínio dedutivo sobre estes institutos. Por meio de uma pesquisa de natureza básica, com objetivo exploratório e coleta de dados por meio de pesquisa bibliográfica e documental, pode-se concluir que essa compatibilidade existe, porém não de maneira absoluta, destacando como um dos maiores entraves a utilização pelos gestores públicos de práticas mais objetivas e alinhadas com uma interpretação mais conservadora da legislação. Simultaneamente, também foi possível identificar experiências e episódios vanguardistas que comprovam que a aplicabilidade do sistema depende mais de coragem administrativa, vontade política e sofisticação hermenêutica do que de mudanças extrínsecas às instituições.

Palavras-chave: Administração Pública. Princípio da Impessoalidade. Gestão por Competências. Seleção por Competências.

\section{ABSTRACT}

The present study analyzed the compatibility of the constitutional principle of impersonality with the use of the selection of people by competences in the scope of federal public universities. Using a theoretical survey on the topics covered, it was possible to conduct a deductive reasoning on these institutes. Through a research of a basic nature, with an exploratory objective and data collection through bibliographical and documentary research, it can be concluded that this compatibility exists, but not in an absolute way, highlighting as one of the major obstacles the use by public managers of more objective practices and aligned with a more conservative interpretation of the legislation. At the same time, it was also possible to identify avant-garde experiences and episodes that prove that the applicability of the system depends more on administrative courage, political will and hermeneutic sophistication than on changes extrinsic to institutions.

Keywords: Public Administration. Principle of Impersonality. Management by Competencies. Selection by Competencies. 


\section{CONSIDERAÇÕES INICIAIS}

Muitas são as discussões travadas acerca de práticas que tornem mais dinâmica e moderna a Administração Pública, adequando-a ao que existe de mais atual em concepções ou políticas de gestão. Área sensível ao debate costuma ser a da gestão de pessoas que, por disposições legais ou pela forma de leitura das normativas, limita-se por vezes à aplicação de sistemas objetivos com fulcro, sobretudo, na elevação do valor da impessoalidade.

O presente artigo busca investigar a compatibilidade entre dois itens que se colocam mandatórios à boa Administração Pública contemporânea. $\mathrm{O}$ primeiro trata-se do Princípio da Impessoalidade, considerando os princípios postos em sede constitucional no sistema jurídico brasileiro para conduzir o trato da coisa pública. O segundo item a ser abordado é a Gestão por Competências, mais especificamente a Seleção por Competências, assunto este que após publicação do Decreto ${ }^{\circ} 5.707$, de 23 de fevereiro de 2006, é um tema que tem sido de certa forma imposto no âmbito da Administração Pública. Mais especificamente ainda, dentro deste item maior, o que se estuda é o subsistema da Seleção por Competências.

Além da importância do tema, a análise ganha outros tons pois toma como cenário as universidades públicas federais, instituições estas que possuem uma complexidade peculiar, pois gozam de prerrogativas específicas, não somente por serem uma autarquia, mas também por fazerem jus a uma medida ainda mais ampliada de autonomia, inclusive por disposição constitucional: a autonomia universitária. E para a realização deste debate o presente artigo iniciará apresentando a teoria referente ao princípio da impessoalidade, assim como da gestão por competências e seleção por competências. Por fim, após a contextualização teórica é realizado um raciocínio dedutivo visando investigar a compatibilidade entre os dois temas escolhidos.

A pesquisa é relevante não somente pelo destaque que o tema tomou na administração pública, mas é oportuna considerando pesquisa realizada pelos autores no Portal de Periódicos CAPES/MEC, assim como na base de dados SciELO (Scientific Electronic Library Online), na data de 28 de setembro de 2016, utilizando-se as palavras-chave: Princípio da Impessoalidade, Seleção por Competências e Administração Universitária, optando-se pela busca de trabalhos publicados de 2010 em diante, pesquisa esta que não obteve retorno de publicação de qualquer natureza, reforçando a relevância do presente estudo e traduzindo seu caráter inédito.

\section{METODOLOGIA}

A presente pesquisa busca desenvolver uma discussão teórica sobre o fenômeno abordado. Por meio do método científico, adota uma abordagem dedutiva, partindo do geral para o específico, e possui natureza básica ao objetivar gerar conhecimento novo de forma que seja considerado útil à ciência, mas sem uma aplicação prática prevista, envolvendo verdades e interesses universais (PRODANOV; FREITAS, 2013). Quanto à abordagem do problema, a pesquisa classifica-se como qualitativa, que para Triviños (1987) identifica tanto características de aparência, quanto de essência e na visão de Matias-Pereira (2010), facilita a interpretação e avaliação dos dados.

Do ponto de vista dos objetivos, esta pesquisa classifica-se como exploratória pois tem como finalidade trazer mais informação sobre o tema investigado, possibilitando sua delimitação e seu delineamento (PRODANOV; FREITAS, 2013). Quanto aos procedimentos técnicos classifica-se como bibliográfica e documental, sendo que na pesquisa documental "a fonte de coleta de dados está restrita a documentos, escritos ou não, constituindo o que se denomina de fontes primárias" (MARCONI; LAKATOS, 2003, p. 174) e a bibliográfica objetiva entrar em contato com escritos sobre o assunto "a partir de material já publicado, constituído principalmente de: livros, revistas, publicações em periódicos e artigos científicos, jornais, boletins, monografias, dissertações, teses, material cartográfico, internet [...]" (PRODANOV; FREITAS, 2013, p. 54). No caso do presente estudo a pesquisa bibliográfica torna-se particularmente importante pois trata-se de uma análise somente teórica sobre o fenômeno. Os principais assuntos e fontes estudados na pesquisa bibliográfica são apresentados no Quadro 1. 
Quadro 1 Assuntos e fontes utilizados na pesquisa bibliográfica

\begin{tabular}{|c|c|}
\hline Estado e contrato social & Dallari (2010); Alves (2001); Streck e Morais (2003) \\
\hline Princípio da Impessoalidade & $\begin{array}{l}\text { Mello (2010); Filho (2010); Mendes, Coelho e Branco (2009); Agra (2010); Constituição } \\
\text { Federal (1988) }\end{array}$ \\
\hline $\begin{array}{l}\text { Administração Pública / Administração de Pessoal } \\
\text { na esfera pública }\end{array}$ & $\begin{array}{l}\text { Matias-Pereira (2010); Meirelles (2011); Lei n.o } 8.112 \text { (1990); Decreto n. } 5.707 \text { (2006); } \\
\text { Decreto n’ } 6.944 \text { (2009) }\end{array}$ \\
\hline Universidade Pública / Autonomia Universitária & Medauar (2007); Ranieri (1994); Di Pietro (2002), Constituição Federal (1988) \\
\hline $\begin{array}{l}\text { Gestão por competências/ Seleção por Compe- } \\
\text { tências }\end{array}$ & $\begin{array}{l}\text { Fleury e Fleury (2001); Bergue (2010), (2011); Brandão (2007), (2012); Silva (2016); Dutra } \\
\text { (2004), (2008); Lopez (2005); Schikmann (2010); Denhardt (2012); Oliveira et al. (2010); Pires } \\
\text { et al. (2010); Bittencourt e Dutra (2008) }\end{array}$ \\
\hline
\end{tabular}

Fonte: elaborado pelos autores (2018).

Importante destacar, por fim, que o presente estudo toma como escopo a seleção dos servidores públicos na Universidade, e não a seleção dos estudantes, e ainda, dentre aqueles, foca nos servidores de carreira técnica, e não docente, tendo em vista a inexistência hoje de etapas de seleção referentes à atuação prática na área, divergindo do caso docente na qual é exigida a prova didática.

\section{DESENVOLVIMENTO TEÓRICO}

\subsection{O Princípio da Impessoalidade na Administração Pública}

Com o intuito de introduzir o princípio da impessoalidade, acredita-se fazer necessária uma breve explicação da formação histórica da administração pública, buscando recuperar o contexto que cria suas condições, o cenário do qual emerge e as razões pelas quais se consolida para então compreender a necessidade do princípio da impessoalidade.

Aristóteles (2005) advertia que o homem, por ser um animal intrínseca e naturalmente político, deveria viver em sociedade e que, por sua condição de reconhecer o bem e o mal, o justo do injusto, poderia superar as sociedades mais simples, para as necessidades diárias mais prementes, em direção à "família do Estado". O Estado vem, portanto, como um acordo de vontades entre os indivíduos para que possam exercer suas faculdades particulares na sociedade ao mesmo passo em que existem para a vida em comunidade (DALLARI, 2010). Com isso, chega-se ao contratualismo como teoria para o surgimento da sociedade civil organizada, quando o contrato social se apresenta como solução para justificar a associação pelo encontro de anseios dos indivíduos, especialmente nas relações entre indivíduos no seio do Estado e, sobretudo, as formas de organização, manifestação e exercício do Poder Público na sociedade contratada, no Estado (DALLARI, 2010).

Com a origem de uma sociedade organizada por um contrato social surge então o problema fundamental do funcionamento do ente estatal, na qual os indivíduos delegam para o Estado uma parcela do poder para que este regule as relações e atue em determinados espectros, garantindo o interesse público, poder este a ser operacionalizado por um governante de plantão e por toda a estrutura de uma gestão deste ente estatal.

Com isso, o soberano concentra em si todos os poderes: de ditame, interpretação e aplicação ou execução da lei (ALVES, 2001). O dito império do contrato social não se diferencia, portanto, do império do governante absoluto. Esta, em suma, é a forma de administração da coisa pública no Estado absolutista, no qual o exercício do poder público se confunde com o próprio poder e a vontade do soberano. O modelo encontra, na ciência da administração, catalogação sob o signo da chamada Administração Pública patrimonialista em que, segundo Matias-Pereira (2010, p. 113):

[...] o aparelho do Estado atua como uma extensão do poder do monarca. Os servidores públicos possuem status de nobreza real. Os cargos funcionam como recompensas, o que gera o nepotismo. Isso contribui para a prática de corrupção e do controle do órgão público por parte dos soberanos. 
É ao longo da transição ocorrida com as revoluções do século XIX, com objetivo principal de combater a corrupção, o nepotismo e o patrimonialismo, em resumo, que surge a Administração Pública burocrática cujos princípios eram "do desenvolvimento, da profissionalização, da ideia de carreira pública, hierarquia funcional, impessoalidade, formalismo" tudo isto direcionado para superar os vícios dos sistemas de operacionalização do poder público anteriormente percebidos (MATIAS-PEREIRA, 2010, p. 113). Para tal combate à corrupção e nepotismo que se tornam necessários processos rígidos de ingresso às carreiras públicas, regras de admissão e outras tantas que busquem evitar abusos e garantir eficiência.

Com isso, pode-se brevemente contextualizar a Constituição Federal Brasileira de 1988 como produto de remontado enredo, dando destaque ao princípio da impessoalidade na Administração Pública, que surge assim pela primeira vez em documento de tal magnitude em solo nacional, com nome e clareza conceitual intuitiva (DI PIETRO, 2002). O Princípio da Impessoalidade traduz e consolida a ideia de que a Administração deve tratar os administrados sem qualquer tipo de discriminação injustificada; nem favoritismos nem perseguições são aceitáveis. Em outras palavras, não podem interferir na gestão da coisa pública interesses privados ou de grupos específicos, nem prevalecer simpatias ou animosidades pessoais, políticas, ideológicas.

José dos Santos Carvalho Filho (2010) ressalta que o princípio da impessoalidade tem por objetivo a igualdade de tratamento aos administrados em situações jurídicas idênticas, apresentando-se assim como outra forma do princípio da isonomia (já apresentado no artigo $5^{\circ}$ da Constituição Federal), devendo voltar-se ao interesse público em detrimento do particular, pois neste segundo caso sempre existirá uma atuação discriminatória. Tem-se em resumo que a isonomia significa "tratar igualmente os iguais e desigualmente os desiguais, na medida de sua desigualdade" de igualdade perante a lei, na lei e diante da lei (MENDES; COELHO; BRANCO, 2009, p. 179). O próprio texto constitucional traz exemplo de aplicação concreta deste princípio, como é o caso da exigência de que o ingresso em cargos ou empregos públicos dependa de concurso público, justamente para que a disputa pelas posições seja feita em condições de plena igualdade entre os candidatos (MELLO, 2010).

O prisma a ser usado para toda análise no caso da Administração é o do interesse público, e a não discriminação também deve ser neste sentido. É aqui que se abre a discussão acerca das desigualdades fáticas que podem justificar políticas ou medidas governamentais, que mesmo que de alguma maneira diferenciem sujeitos, não atentam contra o princípio da impessoalidade, mas, pelo contrário, no tratamento desigual, justificado, garantem o melhor interesse público (AGRA, 2010).

O que se demonstra é que a igualdade não existe, como princípio, com intensidade absoluta, pelo contrário, as diferenciações podem ser ocasionadas por distinções relacionadas com a capacidade e o esforço de cada um e "o que se veda são discriminações gratuitas, destituídas de qualquer sentido" (AGRA, 2010, p. 177). Havendo razão palpável, no entanto, critérios diferenciadores podem ser erguidos sem que ocorra qualquer atentado contra os princípios da isonomia, da igualdade, da impessoalidade e sem que seja prejudicado o interesse público. A impessoalidade, como princípio, deve ser interpretada de forma razoável, verificando a adequação entre os meios e os fins, ou seja, se a finalidade de uma diferenciação é justamente a do interesse público e se os fatores de diferenciação se justificam em razão de tanto, pode-se seguir adiante (AGRA, 2010).

Acredita-se que, em suma, esta seja a revisão literária necessária sobre o princípio da impessoalidade para que se possa discutir a utilização de critérios ou mesmo sistemas de seleção de pessoal para a Administração Pública baseados, especificamente, na análise da pessoa e diferenciação entre indivíduos.

\subsection{A Universidade Pública Federal e sua Autonomia}

No Brasil, a gestão da coisa pública se dá por uma estrutura posta em sede constitucional e em diante. O Estado se organiza de forma tal que possa dar conta de dividir entre as instâncias que o compõem as competências institucionais, as incumbências de prestação de determinados serviços e, por conseguinte, a responsabilidade pela gestão de atividades específicas. Cumpre destacar que a 
menção ao termo serviço público se dá sob a luz das lições de Meirelles (2011, p. 365) que o define como "todo aquele prestado pela Administração ou seus delegados, sob normas e controles estatais, para satisfazer necessidades essenciais ou secundárias da coletividade ou simples conveniências do Estado". O autor bem realiza a ressalva de que o conceito é mesmo generalista, mas afirma que não há meios para se estabelecer significado mais apurado justamente pela variabilidade do item conforme as exigências de cada povo e de cada época (MEIRELLES, 2011).

Sobre as competências postas a cada um dos entes integrantes do Estado importa tornar claro que é o conjunto de órgãos instituídos, cada um para realização de certo serviço público, que forma o que se convenciona chamar Administração Pública e o que se confunde, materialmente, com a organização do Estado e de sua gestão. É diante desta necessária ordenação da Administração Pública que o Estado brasileiro - para o alcance de seus fins - organiza-se mediante uma divisão vertical e decorrente da forma federativa e também uma divisão horizontal, a fim de facilitar a gestão devido a complexidade dos entes, criando assim a Administração Direta e Indireta (MEDAUAR, 2007).

Neste sentido, é possível atribuir não apenas competências aos entes, mas também - e aqui a marca distintiva - personalidade jurídica própria e poder decisórios de maior alcance nos temas a eles afetos (MEDAUAR, 2007). Se nos órgãos públicos há uma supremacia do Estado com suas divisões, para a administração indireta há espécie de supervisão, controle de finalidades, e não uma hierarquia linear de submissão (MELLO, 2010).

As Universidades Federais Brasileiras surgem como espécies de entidades produto da descentralização administrativa pelo critério da especialização técnica, sendo criadas no formato jurídico de autarquias e, como tal, com autonomia - definida esta como uma medida maior de liberdade e capacidade de gestão de seus assuntos, de administração de seus serviços e de patrimônio e pessoal necessários para tanto (MEIRELLES, 2011). Ainda que bastante modulável e indeterminado o conceito desta autonomia atribuída às autarquias, identificada a Universidade como integrante desta categoria de entes estatais há ainda um passo mais a ser dado (DI PIETRO, 2002).
É que a Constituição Federal tratou de consignar a estas instituições de ensino uma reiteração ou reforço desta autonomia, ao prever no próprio texto constitucional que "as universidades gozam de autonomia didático-científica, administrativa e de gestão financeira e patrimonial, e obedecerão ao princípio de indissociabilidade entre ensino, pesquisa e extensão" (BRASIL, 1988, art. 207).

A ideia existente é que a especificidade das atividades desempenhadas por uma universidade e a sua dinâmica própria de funcionamento demandam um tratamento diferenciado ainda diante das demais autarquias (MEDAUAR, 2007). Se historicamente a autonomia universitária surgiu como princípio fundamental para a proteção da instituição de tentativas de cooptação e para a manutenção de sua existência e produção independente, sua chegada ao ordenamento jurídico brasileiro contemporâneo, sobretudo em sede constitucional, recoloca o valor de autonomia como condição de funcionamento da universidade não em defesa contra o Estado mas para que possa fazer parte dele sem submeter-se a ele (RANIERI, 1994).

Dentro deste contexto sensível que é o da autonomia administrativa, mais pertinente ainda a este estudo sua parte que diz respeito à gestão de pessoal, que possibilita a criação de cargos e funções, o estabelecimento de métodos e critérios para seleção, promoção, transferência e demissão dos servidores que integram o quadro institucional, itens estes que configuram e evidenciam a autonomia administrativa, embora estejam vinculados também às disposições constitucionais, como às questões relativas ao orçamento necessário para tanto e ao Regime Jurídico Único do setor público (RANIERI, 1994).

Em que pese a existência de um Regime Jurídico Único (Lei n. ${ }^{\circ} 8.112 / 90$ ) aos servidores públicos federais, incluídos os que atuam nas universidades públicas, ao menos no que diz respeito às disposições gerais, é também de se considerar a existência de carreira própria para estes profissionais, com regulamentação específica e, sobretudo, seu desenvolvimento em um ambiente que opera com maior flexibilidade nas práticas de gestão de pessoas, até mesmo por sua natureza, seus objetivos e atividades a serem desempenhadas. A autonomia universitária e sua manifestação no campo administrativo e, mais especialmente, na gestão de pessoas desponta como 
instituto capaz de legitimar práticas vanguardistas no tema sem que haja, a priori, distanciamento das previsões legais ou desvirtuamento do interesse público.

\subsection{Gestão por Competências}

Ao se falar em competência a primeira ideia que vem à cabeça é a capacidade para fazer, realizar algo. No entanto, Fleury e Fleury (2001) definem competência como sendo uma palavra de conhecimento geral utilizada para designar alguém com qualificação para realizar algo específico. Nos últimos anos, segundo os autores (2001, s/n), o tema entrou para a pauta de estudiosos associado a diferentes níveis de compreensão e significado: "no nível da pessoa (a competência do indivíduo), das organizações (as core competences) e dos países (sistemas educacionais e formação de competências)”. Segundo Bergue (2010), a apropriação do conceito de competência, dentro da esfera da administração pública passa por uma busca pela compreensão de seus múltiplos significados, aos quais ele atribui a similaridade à modelos mentais, com importância fundamental para a construção da compreensão de competência, de forma a possibilitar sua ressignificação dentro da Gestão por Competências. Para Brandão (2012) o conceito de competências assumiu basicamente dois significados ao longo da evolução das teorias administrativas: a realização adequada de atividades e sinônimo de qualidade individual. Durante a Revolução Industrial o termo entrou para o vocabulário dos estudiosos, que o usavam como forma de qualificar o empregado mais preparado para determinado trabalho, o que incentivou a produção de pesquisas e debates sobre o tema (BRANDÃO et al., 2007), podendo ser citados como elementos constitutivos da competência o conhecimento, a habilidade e a atitude (BRANDÃO et al. 2007 apud DURAN, 2000).

Percebe-se que à época do taylorismo e do fordismo o conceito de competência assumia um significado mais tecnicista e racional na medida em que representava as qualificações que o trabalhador deveria aprender para realizar suas atividades e gerar lucro à empresa, visão esta bastante alinhada à corrente de estudiosos americanos, como McClelland, Sencer e Boyatzis, que entendem a competência como o conjunto de conhecimentos, habilidades e atitudes, que credenciam a pessoa à determinada atividade; já outra corrente famosa é representada por autores franceses e ingleses, como Le Boterf, Billis e Rowbottom, Zarifian, entre outros, e apresenta uma visão de competência aliada à ideia de comportamento e a como a pessoa responde aos imprevistos em seu ambiente de trabalho; entendem os conhecimentos, habilidades e atitudes como uma entrega à organização, por parte do trabalhador, e isto determinará o seu desempenho (SILVA, 2016 apud FLEURY, 2001; DUTRA, 2004).

Lopez (2005) afirma que o modelo de gestão por competências surgiu com vistas à consecução dos objetivos organizacionais, por meio da mobilização das competências dos trabalhadores, sendo este um método adequado para ligar os perfis profissionais às capacidades chave da organização. Já Bergue (2010) define a gestão por competências como uma tecnologia gerencial contemporânea, que permite definir competência por meio de suas três dimensões, a partir de suas concepções mais amplas, sendo elas os conhecimentos (requisitos conceituais ou técnicos), as habilidades (capacidade de conversão do conhecimento em ação) e as atitudes (personalidade e postura pessoal e profissional). Com o passar do tempo, o conceito de competência ampliou-se e tornou-se mais complexo em resposta à também maior complexidade da própria sociedade e das relações de trabalho, fruto, entre outras coisas, de novas tecnologias, fazendo com que organizações passassem a considerar também os aspectos sociais e atitudinais, além dos conhecimentos e habilidades necessárias ao trabalhador, cujas abordagens mais modernas acrescentaram o desempenho e o contexto da estratégia organizacional à equação, possibilitando a consecução de resultados econômicos e também sociais, ou seja, a competência passa a ser vista, não só como fonte de valor para a organização, mas também para o indivíduo (PIRES et al. 2005).

Na esfera pública federal o Decreto no 5.707 , de 23 de fevereiro de 2006, institui a política e as diretrizes para o desenvolvimento de pessoal da administração pública federal direta, autárquica e fundacional, definindo gestão por competência como a "gestão da capacitação orientada para o desenvolvimento do conjunto de conhecimentos, habilidades e atitudes necessários ao desempenho das funções dos servido- 
res, visando ao alcance dos objetivos da instituição" (BRASIL, 2006, art. $2^{\circ}$, II). Este foi o marco inicial da tentativa de implementação do modelo na esfera pública federal, demonstrando uma preocupação com o desenvolvimento dos seus profissionais, de forma a atender às novas demandas da sociedade. Contudo, Silva (2016) salienta que a legislação peca em não mencionar as adequações necessárias referentes às diferentes realidades de funcionamento e do contexto onde estão inseridas as instituições públicas para a adoção do modelo de gestão por competências.

A gestão por competências, assim como o planejamento de recursos humanos, a capacitação continuada com base em competências e a avaliação de desempenho e competências, são instrumentos da gestão estratégica e guardam estreita relação entre si, fazendo parte de algo maior e servindo de suporte um ao outro, sendo por meio da gestão por competências que se definirá quais são as competências e perfis profissionais necessários à organização, de forma que haja uma adequação entre o quadro de pessoal e as necessidades desta organização (SCHIKMANN, 2010). Na verdade, a gestão por competências permite que se consiga a separação entre a organização do trabalho e a gestão de pessoas, tendo como ponto de equilíbrio os perfis de competências, que se tornam um elemento comum entre ambos, pois funciona ao mesmo tempo como elemento impulsionador pois permite que a empresa consiga gerir com maior mobilidade e flexibilidade - assim como proporciona ferramentas objetivas, como a medição do esforço formativo e a gestão de perfis, que contribuem para que se crie essa cultura de mobilidade ao premiar a aquisição de competências mediante o desempenho de diversas ocupações (LOPEZ, 2005).

Segundo Oliveira et al. (2010), muitos dos desafios atualmente enfrentados pelos gestores das organizações públicas já foram enfrentados há alguns anos pelos gestores das organizações privadas. Para a autora esses desafios são advindos do novo contexto globalizado e sua notória imprevisibilidade, fato que dificulta ainda mais a tarefa de pensar estrategicamente. Bergue (2010) considera o processo de análise e revisão de modelos gerenciais na administração pública, por vezes apressado e insuficiente, salientando que esta gestão pautada no modelo das organizações privadas pode sim dar certo, desde que se leve em consideração as peculiaridades da esfera pública. Complementa-se o raciocínio com as palavras de Pires et al. (2005), que colocam como principal desafio, ao lidar com a gestão por competências no setor público a correta adequação do uso de metodologias, técnica e mecanismos, onde identifica-se grande dificuldade já na realização da seleção por meio de concursos públicos, por exemplo.

\subsection{Seleção por Competências}

Pode-se dizer que hoje as pessoas são o mais importante ativo de que dispõem as organizações, e como tal, torna-se vital o investimento para atrair os melhores profissionais do mercado (BITTENCOURT; DUTRA, 2008). Brandão (2012) afirma que o recrutamento e a seleção visam à contratação dos profissionais que tenham as competências identificadas como necessárias para o atingimento dos objetivos organizacionais, entendendo-se recrutamento como a atração e seleção como a escolha destes profissionais.

Em comparação à administração pública, o setor privado possui mais liberdade para eleger as técnicas de seleção, já que que não precisa obedecer a princípios constitucionais como legalidade, impessoalidade, moralidade, publicidade e eficiência (BRASIL, 1988; BERGUE, 2010). Tanto a Constituição Federal (art. 37, II) quanto a Lei $n^{\circ} 8.112$, de 11 de dezembro de 1990 versam sobre a investidura em cargos públicos, que se dará por meio de concurso público, podendo ser de provas ou provas e títulos, ou então por meio de nomeação para os cargos em comissão, ambos cumpridos alguns requisitos básicos como nacionalidade brasileira, quitação das obrigações militares e eleitorais, idade mínima de 18 anos, entre outros. Neste sentido, Bergue (2010) afirma que na administração pública o objetivo geral da gestão de pessoas é composto basicamente pelas ações de suprimento, manutenção e desenvolvimento, e ocorre de maneira peculiar pois envolve métodos e procedimentos diversos da esfera privada. Segundo o autor o processo de suprimento de pessoas nas organizações públicas denomina-se processo admissional e divide-se em quatro fases bem definidas: recrutamento, seleção, admissão e registro. 
$\mathrm{O}$ autor explica que o processo de recrutamento é uma sucessão de atos administrativos complexos, que envolve a identificação da necessidade, a análise de existência de vagas já previstas em lei, elaboração do edital e abertura do concurso, processo e homologação de inscrições. Salienta ainda que é importante estar claro que quaisquer condições, restrições, imposições ou exigência pessoal no edital que não estejam contempladas em lei para o exercício do cargo, violam tanto o princípio da legalidade, quanto os princípios da isonomia e da impessoalidade. Além disso, destaca a necessidade da reserva legal de vagas para portadores de deficiência, e a possibilidade de igualdade de condições em relação aos demais candidatos no que se refere ao conteúdo e instrumentos de avaliação, conforme já comentado.

Já a fase subsequente é a de seleção de pessoas, composta por um conjunto de atos destinados a avaliar os candidatos e ordená-los em um rol de desempenho individual, tendo como critérios os previamente definidos pelo edital do concurso, objetivando "alcançar uma situação de máxima adequação e eficiência do indivíduo em relação ao cargo" (BERGUE, 2010, p. 536). O autor ainda destaca que servirá de subsídio aos processos de recrutamento e seleção o adequado desenho de cargos, sendo este uma condição necessária, pois é no perfil do cargo que a administração terá os parâmetros básicos para a formulação dos instrumentos de avaliação do candidato.

$\mathrm{Na}$ concepção de Oliveira (2011), a Lei no 11.091 de 12 de janeiro de 2005 (que versa sobre o plano de carreira dos técnicos administrativos em educação) estabeleceu novos padrões para a estruturação dos cargos dentro das Instituições Federais de Ensino Superior. O autor alega que a lei valorizou as competências individuais associadas às organizacionais, pois classifica os cargos seguindo critérios que não consideram apenas a escolaridade, mas também outros requisitos e habilidades, como responsabilidade, conhecimentos, experiência, risco e esforço físico, de modo a tentar contemplar as reais necessidades institucionais.

O Decreto no 5.825 de 29 de junho de 2006 (que trata do plano de desenvolvimento dos integrantes do plano de carreiras da Lei nº11.091/05) também prevê a implementação de programa de capacitação e aperfeiçoamento que, entre outros, promova cursos de iniciação ao serviço público, visando proporcionar ao recém ingressante conhecimentos referentes às funções do Estado, às especificidades do serviço público, à missão da Instituição Federal de Ensino, à conduta do servidor público e também a sua integração no ambiente institucional (BRASIL, 2006b). Na concepção de Pires et al. (2005), a inclusão de curso de formação inicial como etapa da seleção por concurso público seria uma alternativa plausível que possibilitaria a identificação de competências individuais e outros aspectos do comportamento dos candidatos. Os autores ainda apontam como alternativa a criação de cargos genéricos, citando como exemplo o cargo de Analista do Banco Central do Brasil, porém a genericidade seria amenizada por meio da especificação de subáreas.

Já o Decreto no 6.944 de 21 de agosto de 2009 (que entre outros assuntos dispõe sobre normas gerais relativas a concursos públicos) estabelece que, no caso da realização do concurso em duas etapas, a segunda etapa seja constituída de curso ou programa de formação, de caráter eliminatório e classificatório, ressalvada disposição diversa especificada em lei. O Decreto também prevê que se houver aplicação de prova oral, defesa de memorial, teste de aptidão física, prova prática, avaliação psicológica e/ou curso ou programa de formação inicial, estes devem estar contemplados no edital do certame, que deverá descrever detalhadamente a metodologia de avaliação, a pontuação mínima para classificação e a forma de divulgação do resultado (BRASIL, 2009). Na visão de Costa et al. (2014), a legislação além de possibilitar a realização de duas etapas em concursos públicos, ainda permite a utilização de várias técnicas, desde que devidamente justificadas e detalhadamente descritas no edital do certame. Para os autores, cabe a cada instituição avaliar, com base em aspectos legais, financeiros e operacionais quais os instrumentos mais adequados para selecionar os servidores que atendam às suas necessidades.

Na concepção de Schikmann (2010), existe uma limitação no escopo de atuação dos servidores, devido à forma como é realizada a descrição de cargos, 0 que desestimula a multifuncionalidade e a visão sistêmica. Isso porque, segundo a autora, o recrutamento e a seleção no setor público são baseados nos cargos e não em competências, e acabam sendo descritos de 
forma genérica, permitindo a alocação de pessoas em áreas com características muito diversas, sem suprir as reais necessidades relacionadas às competências necessárias à realização das atividades e, inclusive, estimulando os desvios de função. Ideia compartilhada por Bergue (2011) quando o autor afirma que há que se repensar a estrutura dos cargos e carreiras de forma a deslocar a ênfase sobre as atribuições do cargo, onde os legisladores acabam por tentar esgotar o elenco de atividades que poderiam ser desenvolvidas pelo seu ocupante, para as competências desejadas.

Segundo Pires et al. (2005, p. 27), as atividades de recrutamento e seleção representam uma dimensão crucial do modelo de gestão de pessoas por competências, pois caso "sejam bem conduzidas, as organizações terão maior probabilidade de recrutar profissionais alinhados com as estratégias e a missão da organização". Por fim, Bergue (2010) destaca que a administração pública necessita de urgente modernização de procedimentos e mesmo de atitudes, especialmente com relação à gestão de seu pessoal, sem a qual restará comprometido o atendimento aos interesses da coletividade. Para ele, uma gestão de pessoas estratégica permitirá que se avalie também a questão do custo decorrente da necessidade de admissão de novos servidores, fato que o autor chama de razão entre o custo total de realização de um processo de admissão de pessoal e o número de admitidos. Este custo tende a ser maior quanto menor o número de ingressos, por isto a opção da administração pública por realizar concursos em blocos, o que consome tempo e muitas vezes desfalca a atividade, podendo apresentar queda de produtividade ou da qualidade dos serviços prestados.

\section{CONSIDERAÇÕES FINAIS}

Longe de querer por um ponto final na discussão em voga, pois a mesma apresenta-se por demais complexa, podendo render ainda outros estudos e considerações, o presente estudo procurou responder, à luz dos autores ora aqui apresentados, quais os pontos de convergência, ou não, entre o princípio constitucional da impessoalidade e o sistema de seleção por competências no âmbito das universidades públicas federais brasileiras.
Percebe-se que tal resposta não configura-se tão fácil assim, não podendo esta resumir-se simplesmente a um sim ou um não, quanto à compatibilidade entre os institutos, haja vista a grande complexidade pela qual se reveste a atuação da administração pública. Pode-se dizer, de uma maneira generalizada, que num primeiro momento existe compatibilidade, pois ao estudar-se tal princípio, nada houve que o declare incompatível com uma seleção realizada por competências. Tanto é verdade que Costa et al. (2014) relatam a experiência da Universidade Federal do Pará (UFPA), que desenvolveu um concurso público por competências, baseado no mapeamento de competências organizacionais e individuais previamente realizado naquela instituição, elaborando-se questões específicas para três cargos: Administrador, Psicólogo Clínico e Psicólogo Educacional. Os dados apontados pelos autores indicam que o desempenho dos candidatos selecionados tomando como base as competências requeridas atenderam melhor às expectativas da instituição em relação àqueles selecionados pelos métodos tradicionais.

A seleção por competências, enquanto ferramenta estratégica utilizada para uma gestão mais eficiente e eficaz, que busca captar para a organização os profissionais mais capacitados para a consecução dos objetivos organizacionais, só tem a acrescentar à gestão pública, visto serem os institutos da eficiência e da eficácia também seus objetivos. Mas, para que haja a compatibilidade entre ambos, há de se levar em consideração, sobretudo, a questão legal, ou seja, para que o administrador público consiga atuar dentro do modelo de seleção por competências, ele deverá adequar as fases e características do processo aos rigores e limites da lei. Lei esta que, entre outras coisas, estabelece que a Administração Pública deverá atuar de forma impessoal no tratamento igualitário e isonômico a ser dispensado aos administrados.

Segundo Pires et al. (2005), as especificidades do processo de recrutamento e seleção na administração pública são de certa forma restritivas por não permitirem a avaliação de determinados comportamentos e atitudes, sendo os principais instrumentos de seleção externa as provas e os títulos, que servem para dimensionar a abrangência do nível de conhecimento, além do desempenho acadêmico e cognitivo dos candidatos, ou seja, há uma priorização do nível 
de conhecimentos e habilidades, sem considerar os aspectos atitudinais. Os autores destacam que não existe avaliação de aspectos relacionados à conduta pessoal e interpessoal e, consequentemente, o processo seletivo torna-se falho pois escolhe candidatos com muitas qualidades intelectuais, mas não necessariamente com o perfil adequado para o cargo pleiteado, gerando, não raras vezes, problemas de adaptação, de relacionamento no ambiente de trabalho, de baixa produtividade e altos índices de afastamento devido a doenças profissionais. Ainda, afirma que muitas organizações têm optado em acrescentar mais uma etapa ao processo seletivo como forma de tentar contornar essas dificuldades: a realização de cursos de formação. No entanto, Brandão (2012) afirma ser possível avaliar determinadas competências comportamentais aplicando-se provas com questões que levem o candidato a refletir e informar, por meio das alternativas, como reagiria em determinada situação de trabalho.

Depreende-se quanto ao princípio da impessoalidade, após o estudo aqui realizado, que este impõe à Administração Pública o dever de não proceder na discriminação de indivíduos injustificadamente, guardando tratamento igualitário não apenas formalmente, mas também de forma material. A evolução da concepção deste princípio, dentro do que este representa hoje em uma democracia, deu-se conjuntamente com a evolução do próprio Estado, tendo suas raízes nos conceitos de igualdade e de isonomia. Este princípio, assim como todos os outros da administração pública, deve sempre ser analisado sob o prisma da supremacia do interesse público e à luz dos demais princípios que regem a administração pública. Portanto, não se trata de princípio inflexível e absoluto, como bem explicou Agra (2010), ao afirmar que o princípio deve ser interpretado de forma razoável na adequação entre meios e fins, de forma a permitir, até certo ponto, diferenciação plausivelmente justificada pela supremacia do interesse público.

Da mesma forma, quando se reflete a respeito da autonomia de que dispõe a universidade pública federal, mesmo estando o administrador público vinculado ao princípio da impessoalidade, resta-lhe ainda espaço para atuação onde é permitido agir com certa discricionariedade e flexibilidade no que diz respeito às seleções públicas, dada a autonomia administrativa conferida pela Constituição Federal. Por se tratar de figura peculiar no rol de instituições públicas, com traços particulares, possuem mais ampla a possibilidade de exercícios no sentido de caminhar em práticas de gestão de pessoas que operacionalizem o conceito de impessoalidade em favor do interesse coletivo.

No entanto, percebe-se ao longo do presente estudo que existe um desafio na adoção de critérios subjetivos pelos gestores públicos, que não raro recorrem à segurança de práticas mais conservadoras, objetivas e irrefutavelmente impessoais ao invés de critérios que busquem a seleção para escolha daqueles capazes a desempenhar, com maior competência e adequação, determinado serviço público. Assim, embora, ressalvadas as devidas limitações impostas pela legislação, exista compatibilidade entre a seleção por competências com o instituto da impessoalidade - que apesar de ser um ditame constitucional, não é absoluto, conforme caracterizado no presente estudo -, acaba sendo mais fácil para o gestor público continuar administrando segundo modelos mais tradicionalistas, haja vista ser a seleção por competências um processo mais trabalhoso e que depende de técnicas específicas, além de pessoal habilitado a aplicá-las. Conforme demonstrado na legislação e literatura, a maior parte das seleções são realizadas por meio de provas que abrangem conteúdos teóricos, exigindo dos candidatos elevado nível de conhecimento, desprezando-se a aferição das habilidades e do caráter atitudinal do indivíduo. A exigência de prova de títulos, que é uma possibilidade oferecida pela legislação vigente, reforça ainda mais a dimensão acadêmica dos processos seletivos.

Outra consideração a se fazer diz respeito à introdução de curso de formação, com caráter eliminatório, como etapa do processo seletivo, a exemplo dos concursos para carreira militar e diplomática, apontada por alguns autores como alternativa de avaliação de habilidades e atitudes dos candidatos. Porém, entende-se que para tanto é necessário que tal prerrogativa esteja expressa em lei, como é o caso das carreiras citadas, pois, de outra forma, desrespeitaria outro princípio constitucional, o da legalidade, sem deixar de mencionar também o aumento de custos para a Administração Pública que a adoção desta prática traria. 
Um fator importante dentro do raciocínio aqui seguido, diz respeito à questão legal como sendo um fator limitador quanto às aplicabilidades plenas de uma seleção por competências. Segundo Oliveira (2011), conforme estudo realizado na Universidade Federal de Pernambuco (UFPE), na avaliação dos gestores, o processo de seleção por competências só poderia ser implantado na instituição caso a legislação fosse modificada, sendo esta também uma justificativa para a manutenção dos sistemas tradicionais de seleção. Os pontos mais críticos que devem ser observados pelo gestor público quando da adoção do modelo de seleção por competências, e que o colocariam numa situação mais delicada e passível de se ferir o princípio da impessoalidade, seriam justamente os relativos às fases de planejamento do certame e de seu edital, visto que é justamente aí que existe a possibilidade de se enveredar por caminhos mais subjetivos, podendo inclusive levar o gestor a responder judicialmente por um edital mal formulado e que não leve em consideração todas as variáveis e condicionantes envolvidas.

Por fim, entende-se que, apesar da compatibilidade entre o princípio constitucional da impessoalidade e a seleção por competências no âmbito da universidade pública federal brasileira, ainda são várias as barreiras ou condicionantes impostos pela legislação vigente, fato que não facilita a atuação do gestor público. Assim como existem também questões relativas à cultura presente no serviço público, à falta de pessoal capacitado, de infraestrutura adequada, ou mesmo questões políticas, que tornam o processo mais dificultoso e trabalhoso do que na esfera privada. Entende-se que, enquanto a gestão por competências não for incorporada como uma política institucional pública muito pouco pode ser feito, mas primeiramente deve-se pensar na seguinte questão norteadora para todos os processos subsequentes: que universidade estamos construindo, ou melhor, que universidade queremos construir?

\section{REFERÊNCIAS}

AGRA. Walber de Moura. Curso de direito constitucional. Rio de Janeiro (RJ): Forense, 2010.

ALVES, Marcelo. Leviatã: o demiurgo das paixões: uma introdução ao contrato hobbesiano. Florianópolis (SC): Letras Contemporâneas, 2001. ISBN 8585775688.

ARISTÓTELES. Politica: texto integral. São Paulo (SP): Martin Claret, 2005. (Coleção a obra-prima de cada autor 61).

BERGUE, Sandro Trescastro. Gestão de Pessoas em Organizações Públicas. Caxias do Sul: Educs, 2010.

BERGUE, Sandro Trescastro. Modelos de Gestão em Organizações Públicas: Teorias e Tecnologias para Análise e Transformação Organizacional. Caxias do Sul: Educs, 2011.

BITTENCOURT, Dênia Falcão de; DUTRA, Ademar. Gestão de Pessoas II: Livro Didático. Palhoça: Unisul Virtual, 2008.

BRANDÃO, Hugo Pena; GUIMARÃES, Tomás de Aquino. Gestão de Competências e Gestão de Desempenho: tecnologias distintas ou instrumentos de um mesmo construto? RAE - Revista de Administração de Empresas, São Paulo, jan/mar 2001.

BRANDÃO, Hugo Pena; BORGES-ANDRADE, Jairo Eduardo. Causas e efeitos da expressão de competências no trabalho: para entender melhor a noção de competência. Revista de Administração Mackenzie - RAM, São Paulo, v. 8, n. 3, p. 32-49, 2007.

BRANDÃO, Hugo Pena. Mapeamento de Competências: métodos, técnicas e aplicações em gestão de pessoas. São Paulo: Atlas, 2012.

\section{BRASIL. Constituição da República Federativa do}

Brasil de 1988. Disponível em: <http://www.planalto. gov.br/ccivil_03/constituicao/constituicaocompilado. htm>. Acesso em: 20 ago. 2018. 
BRASIL. Lei 8.112, de 11 de dezembro de 1990. Dispõe sobre o regime jurídico dos servidores públicos civis da União, das autarquias e das fundações públicas federais. Disponível em: $<$ http://www. planalto.gov.br/CCIVIL_03/Leis/L8112compilado. htm>. Acesso em: 20 ago. 2018

BRASIL. Lei no 11.091, de 12 de janeiro de 2005. Dispõe sobre a estruturação do Plano de Carreira dos Cargos Técnico-Administrativos em Educação, no âmbito das Instituições Federais de Ensino vinculadas ao Ministério da Educação, e dá outras providências. Disponível em: < http://www. planalto.gov.br/ccivil_03/_ato2004-2006/2005/lei/ L11091compilado.htm>. Acesso em: 20 ago. 2018.

BRASIL. Decreto n. ${ }^{\circ}$ 5.707, de 23 de fevereiro de 2006. Institui a política e as diretrizes para o desenvolvimento de pessoal da administração pública federal direta, autárquica e fundacional e regulamenta dispositivos da Lei no 8.112, de 11 de dezembro de 1990. Diário Oficial da União, Poder Executivo, Brasília, DF, 24 fev. 2006. Seção 1, p. 3. Disponível em: <http:// www.planalto.gov.br/ccivil_03/_Ato2004-2006/2006/ Decreto/D5707.htm>.Acesso em: 20 ago. 2018.

BRASIL. Decreto No 5.825, de 29 de junho de 2006b. Estabelece as diretrizes para elaboração do Plano de Desenvolvimento dos Integrantes do Plano de Carreira dos Cargos Técnico-Administrativos em Educação, instituído pela Lei no 11.091 , de 12 de janeiro de 2005. Diário Oficial da União, Poder Executivo, Brasília, DF, 30 jun. 2006. Disponível em: $<$ http://www.planalto.gov.br/ccivil_03/_ato20042006/2006/decreto/d5825.htm>. Acesso em: 20 ago. 2018.

BRASIL. Decreto no 6.944, de 21 de agosto de 2009. Estabelece medidas organizacionais para o aprimoramento da administração pública federal direta, autárquica e fundacional, dispõe sobre normas gerais relativas a concursos públicos, organiza sob a forma de sistema as atividades de organização e inovação institucional do Governo Federal, e dá outras providências. Disponível em: < http://www. planalto.gov.br/ccivil_03/_ato2007-2010/2009/decreto/d6944.htm>. Acesso em: 20 ago. 2018.
CARVALHO FILHO, José dos Santos. Manual de direito administrativo. Rio de Janeiro: Lumen Juris, 2010.

COSTA, Thiago dias et al. Concurso Público por Competências: um estudo piloto em uma Instituição Federal de Ensino. Anais do XIV Colóquio Internacional de Gestão Universitária - CIGU. Florianópolis, 2014. Disponível em: <https://repositorio.ufsc.br/bitstream/handle/123456789/132067/2014-359.pdf? sequence=1>. Acesso em: 20 ago. 2018.

DALLARI, Dalmo de Abreu. Elementos de teoria geral do Estado. 29. ed. São Paulo: Saraiva, 2010. ISBN 9788502081451

DENHARDT, Robert. B. Teorias da administração pública. Tradução técnica e glossário Francisco G. Heidmann. São Paulo: Cengage Learning, 2012.

DI PIETRO, Maria Sylvia Zanella. Direito administrativo. São Paulo: Atlas, 2002.

FLEURY, Afonso. FleURY, Maria Tereza. Construindo o conceito de competências. Revista de Administração Contemporânea. Edição especial, 2001. Disponível em: <http://www.scielo.br/pdf/rac/ v5nspe/v5nspea10.pdf>. Acesso em: 20 ago. 2018.

GIL, Antônio Carlos. Métodos e técnicas de pesquisa social. 6. ed. São Paulo: Atlas, 2008.

LAKATOS, Eva Maria; MARCONI, Marina de Andrade. Fundamentos de metodologia científica. 6. ed. São Paulo: Atlas, 2007.

LOPEZ, Javier Fernandez. Gestión por Competencias: Un modelo estratégico para la dirección de recursos humanos. Pearson Educación. Madri, 2005.

MATIAS-PEREIRA, José. Curso de Administração Pública: foco nas instituições e ações governamentais. São Paulo: Atlas, 2010.

MEDAUAR, Odete. Direito administrativo moderno. São Paulo: Editora Revista dos Tribunais, 2007. 
MEIRELLES, Hely Lopes. et al. Direito administrativo brasileiro. São Paulo: Malheiros, 2011

MELLO, Celso Antônio Bandeira de. Curso de direito administrativo. São Paulo: Malheiros, 2010.

MENDES, Gilmar Ferreira; COELHO, Inocêncio Mártires; BRANCO, Paulo Gustavo Gonet. Curso de direito constitucional. São Paulo: Saraiva, 2009.

MICHAELIS, Dicionário Brasileiro da Língua Portuguesa, Editora Melhoramentos, 2015. Disponível em: <http://michaelis.uol.com.br/busca?id=ZpP2>. Acesso em: 20 ago. 2018.

OLIVEIRA, Márcio Medeiros. Difusão do sistema de Gestão de Pessoas por Competências em Instituições Federais de Ensino Superior na Região Nordeste do Brasil. Dissertação - Universidade Federal da Paraíba. Programa de Pós Graduação em Administração. João Pessoa - 2011. Disponível em: < https://repositorio.ufpb.br/jspui/bitstream/ tede/3791/1/arquivototal.pdf $>$. Acesso em 20 ago. 2018 .

OLIVEIRA, Olívia Bahia et al. Estratégias de Flexibilização na Gestão de Recursos Humanos: Uma Análise a Partir das Reformas Administrativas. Anais do XXXIV ENANPAD, Rio de Janeiro, 2010. Disponível em: <http://www.anpad.org.br/admin/ pdf/apb2024.pdf>. Acesso em: 20 ago. 2018.

PIRES, Alexandre Kalil et al. Gestão por competência em organizações do governo. Brasília: ENAP, 2005.

PRODANOV, Cleber Cristiano; FREITAS, Ernani Cesar de. Metodologia do Trabalho Científico: Métodos e Técnicas de Pesquisa. Novo Amburgo: Feevale, 2013.
RANIERI, Nina. Autonomia universitária: as universidade públicas e a Constituição Federal de 1988. São Paulo: Editora da Universidade de São Paulo, 1994.

ROUSSEAU, Jean-Jacques. Do contrato social ou princípios do direito político: texto integral. São Paulo: Martin Claret, 2001.

SCHIKMANN, Rosane. Gestão Estratégica de Pessoas: bases para a concepção do Curso de Especialização em Gestão de Pessoas no Serviço Público. In (org.) CAMÕES, Marizaura Reis de Souza; PANTOJA, Maria Júlia; BERGUE, Sandro Trescastro. Gestão de pessoas: bases teóricas e experiências no setor público/organizado. Brasília: ENAP, 2010.

SILVA, Ana Corina Faustino da. Recrutamento e seleção por competências: análise da adequação dos concursos públicos para a admissão de servidores técnico-administrativos em educação à gestão por competências na UFSC. Dissertação (mestrado profissional) - Universidade Federal de Santa Catarina. Programa de Pós Graduação em Administração Universitária. Santa Catarina, 2016. Disponível em: $<$ http://tede.ufsc.br/teses/PPAU0108-D.pdf $>$. Acesso em: 30 set. 2016.

STRECK, Lenio Luiz; MORAIS, Jose Luis Bolzan de. Ciência politica e teoria geral do Estado. 3. ed. Porto Alegre: Livraria do Advogado, 2003.

TRIVIÑOS, Augusto Nibaldo Silva - Introdução à pesquisa em ciências sociais: a pesquisa qualitativa em educação. São Paulo: Atlas, 1987. 